Revista Portuguesa de História

t. XXXI, Vol. I(1996)

\title{
CARACTERÍSTICAS DA CULTURA PORTUGUESA: ALGUNS ASPECTOS E SUA INTERPRETAÇÃ O*
}

\author{
JOSÉ M. AMADO MENDES \\ (Universidade de Coimbra)
}

\section{Noções de Cultura}

Até cerca de meados do século XX, era frequente identificar "cultura" com as conquistas do espírito, ao longo dos tempos, ao invés de "civilização", mais ligada ao progresso material'. Porém, nas últimas décadas, graças à evolução, entre outros, dos estudos históricos, antropológicos e sociológicos, tem vindo a reforçar-se a ideia de que não basta falar de cultura, em geral, dada a existência de diversos tipos de cultura. Daí o facto de hoje se usarem frequentemente expressões como: cultura erudita e cultura popular, cultura de elites e cultura de massas, cultura literária, filosófica ou cultura científica ou técnico-científica; cultura material e cultura empresarial; culturas nacionais e culturas regionais, etc. Assim,

* O texto que ora se publica, ampliado e anotado, serviu de base a uma conferência proferida na "Faculty of Education-Kyoto University" (Japão), no dia 23 de Fevereiro de 1996.

Perspectiva ainda patente em T. S. Eliot, Notes towards the definition of culture, Londres, Faber \& Faber, 1948 (reed., 1961). 
podem dar-se várias definições de cultura, consoante a perspectiva que se adoptar. Vejamos, a título de exemplo, três noções diferentes de cultura.

Em sentido absoluto, filosófico e pedagógico-que, a partir de Cícero, aparece como cultura animi, cultura do espírito - , pode definir-se como «a acção que o homem exerce de si, por si e sobre si, visando uma auto-transformação, ou seja, o processo de evolução do espírito humano, a que podemos chamar o processo de humanização do homem»";

Sob o ponto de vista etnológico, A. Jorge Dias definiu cultura como «sistema de ideias, sabedoria, atitudes, técnicas, equipamento material, padrões de comportamento, literatura oral, danças, música, crenças mágicas e religiosas que caracterizam qualquer sociedade e constituem o seu património social» ${ }^{3}$;

Por último, a partir dos anos 20 do nosso século, começou a ter grande divulgação o conceito de cultura material. Esta tem por objecto a história dos «elementos, das pessoas e das coisas do processo de produção e de reprodução da vida material das sociedades no curso dos diversos estádios de desenvolvimento desses elementos». Estes são assim constituídos: a) os meios de trabalho; b) o objecto do trabalho, ou seja, as riquezas naturais; c) a experiência do homem no processo de produção e, d) por último, a utilização dos produtos materiais ${ }^{4}$. Trata-se, pois, não de uma cultura de elite, mas sim de uma cultura do «grosso da população» ${ }^{5}$.

2 A. Jorge Dias, «Cultura (conceito etnológico)», Joel Serrão (dir.). Dicionário de História de Portugal, vol. I, Iniciativas Editoriais, 1963, p. 767.

${ }^{3}$ A. Jorge Dias, idem, p. 768.

‘ Richard Bucaille e Jean-Marie Pezes, «Cultura material», Enciclopédia Einaudi, vol. 16; Homo - Domesticação - Cultura material, Lisboa, Imprensa Nacional-Casa da Moeda, 1989, p. 31.

${ }^{5}$ Idem, p. 21. 
Atendendo à similitude de diversos tipos de cultura, entre si, e à distinção que os opõe aos tipos de um outro grupo, C. P. Snow, na sua conhecida obra sobre o assunto, notou a existência de duas culturas: científica e humanística. Referindo-se à primeira, afirma: «De facto, a cultura científica é realmente uma cultura, não só no sentido intelectual como antropológico» ${ }^{6}$.

$\mathrm{Na}$ caracterização da cultura portuguesa, que procurarei fazer seguidamente, reportar-me-ei essencialmente à cultura em termos genéricos-filosófica, literária, linguística e artística—, relacionada com as Humanidades, por se tratar da perspectiva adoptada pela maioria dos autores que têm focado o assunto. Porém, terei igualmente presente os outros tipos de cultura, nos quais se integram alguns dos elementos a focar.

\section{Cultura(s) Portuguesa(s)?}

Numa mesa-redonda realizada na cidade do Porto em 1992, debateu-se a seguinte temática: «Existe uma cultura portuguesa?» ${ }^{7}$. Por sua vez, enquanto alguns autores se têm batido pela existência de uma filosofia portuguesa (como José Marinho e Lopes Praça $)^{8}$, procurando estudá-la e divulgá-la, outros têm-na pura e simplesmente negado. Em contrapartida, não suscita dúvidas a existência de, por exemplo, uma literatura ou uma arte portuguesas, ou mesmo um folclore português, para já não falar de outros

CP. Snow, The Two Cultures and a Second Look. An expanded version of the Two Cultures and the Scientific Revolution, Cambridge University Press, 1969.

'Augusto Santos Silva e Vítor Oliveira Jorge, Existe uma cultura portuguesa?. Porto, Edições Afrontamento, 1993.

${ }^{8}$ Lopes Praça, História da Filosofia portuguesa, Fixação do texto, introdução, notas e bibliografia por Pinharanda Gomes, 3. ed., Lisboa, Guimarães Editores, 1988. 
domínios da realidade histórica portuguesa, a começar, desde logo, pela respectiva língua.

Mas, voltando à questão incial, existirá, efectivamente, uma cultura portuguesa? Obviamente que responderei afirmativamente, defendendo que há, de facto, não só uma cultura portuguesa como culturas portuguesas. Para comprovar a asserção, basta estudar-se a História de Portugal e, bem assim, as múltiplas realizações, de todo o tipo, levadas a cabo pelo povo português, em mais de oito séculos. Todavia, se ainda persistirem dúvidas, elas dissipar-se-ão após uma análise cuidada das obras de alguns dos mais eminentes historiadores da cultura portuguesa, desde Jaime Cortesão, António Sérgio e Raul Proença a Joaquim de Carvalho, de Jorge Dias e António José Saraiva a José Sebastião da Silva Dias, para me referir apenas aos já falecidos.

Mesmo se, além dos aspectos genéricos e comuns, de âmbito nacional, desejarmos analisar outros mais específicos-por estratos socioprofissionais, regiões e organizações/instituições ${ }^{9}$ - , chegaremos à conclusão de que, com um substrato cultural de grande amplitude e cariz nacional, coincidem formas de cultura mais circunscritas, que poderemos designar também culturas portuguesas. Entre outras, poderemos referir os seguintes tipos: erudita e popular, urbana e rural, empresarial e operária.

' T. S. Eliot distingue três sentidos (ou níveis) de uma cultura: individual, de um grupo ou classe e de toda uma sociedade (T. S. Eliot, op. cit., p. 21). Sobre as diversas culturas-ou o "pluralismo cultural"-, ver ainda Paul Feyerabend, Adeus à razão (trad. do inglês), "Biblioteca de Filosofia Contemporânea", Lisboa, Ed. 70, 1991, p. 319-326. 


\section{Elementos Caracterizadores da Cultura Portuguesa}

\subsection{Identidade nacional e História}

Portugal, como nação, remonta ao século XII, sendo por isso um dos países mais antigos do Mundo. Como sublinhou José Mattoso, na obra intitulada Identificação de um País, «a noção de identidade nacional, isto é a diferenciação do regnum (kingdom) como unidade política definida por um poder monárquico sobre um território limitado e os seus habitantes, parece precoce e suficientemente clara desde a primeira metade do século XIII. Esta resultava da transposição da noção de soberania senhorial para o âmbito e as dimensões do reino» ${ }^{10}$.

Com a conquista definitiva do "reino" do Algarve, em 1249 (reinado de D. Afonso III), Portugal vê definidas as suas fronteiras, as quais permaneceram, até à actualidade, praticamente sem alterações. Por sua vez, com a crise — política e socioeconómicade 1383-85, a consciência nacional acabaria por se tornar suficientemente sólida, passando a ser partilhada por todas as camadas sociais. Esta longa história, sob uma perspectiva político-cultural, ainda poderá remontar a alguns séculos atrás, se considerarmos o legado deixado pelos povos que, de longa data, habitaram a Península Ibérica (celtas, lusitanos, romanos, "bárbaros", árabes, etc). Trata-se, pois, do chamado "legado pré-nacional", cujos traços fundamentais foram já devidamente salientados por Orlando Ribeiro". Acrescente-se que a receptividade da cultura portuguesa

${ }^{10}$ José Mattoso, Identificação de um País. vol. II: Composição, Lisboa, Ed. Estampa, 1985, p. 211.

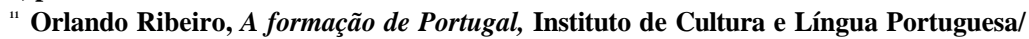
Ministério da Educação, 1987, p. 25-42. 
à influência de outras culturas tem sido uma constante, ao longo da história. Daí que já se tenham identificado, como fontes ou matrizes da nossa cultura, as seguintes: galega, castelhana, catalã, italiana, francesa, inglesa e alemã ${ }^{12}$.

Dada esta riquíssima e prolongada vivência histórica, em que medida é que isso se reflecte na cultura portuguesa? É bem possível que tal esteja na origem de uma considerável receptividade à História Pátria por parte dos Portugueses e, inclusive, tenha contribuído para um certo culto "historicista" em Portugal. Como salientou um dos mais notáveis historiadores da nossa cultura António José Saraiva—, «com o desinteresse pela filosofia contrasta em Portugal o interesse pela história. Qualquer que seja a época, encontramos entre nós uma historiografia abundante e de excelente qualidade, comparável à das grandes literaturas europeias e certamente não inferior à espanhola» ${ }^{13}$. Corroborando as palavras do autor, pode acrescentar-se que esse interesse e gosto pela história não diminuíram em nossos dias, pelo que, em trabalho recente, se focava exactamente «a emergência da História» ${ }^{14}$. Por outro lado, não menos surpreendente é o facto de, ultimamente, não só terem aparecido novas revistas de História, como se terem publicado, a partir de 1977, cinco Histórias de Portugal ${ }^{15}$ — uma das quais ainda por concluir-, tendo-se uma delas (dirigida por José Matto-

Carlos Eduardo de Soveral, «Trajectória da cultura portuguesa», Ao ritmo da Europa, Lisboa, Ed. Verbo, 1962, pp. 273-274.

${ }^{13}$ António José Saraiva, A cultura em Portugal. Teoria e História, livro I: Introdução geral à cultura portuguesa, Lisboa, Livraria Bertrand, 1981, p. 93-94.

${ }^{14}$ António Manuel Hespanha, «A emergência da História», Penélope, $n^{o}$. 5, 1991, p. 9-25.

${ }^{15}$ Uma da autoria de Joaquim Veríssimo Serrão e as restantes dirigidas, respectivamente, por: José Hermano Saraiva, Joel Serrão e Oliveira Marques, José Mattoso e João Medina. 
so) transformado num autêntico "best-seller", uma vez que já se terão vendido cerca de 100000 exemplares ${ }^{16}$.

Acrescente-se, todavia, que o próprio autor citado (A. José Saraiva) formula uma outra hipótese, para explicar o gosto e o interesse pela História, da parte dos Portugueses: «Outra explicação para esta importância da historiografia seria um contemplativismo passadista, uma procura da idade de ouro no passado - uma forma, afinal, de saudosismo» ${ }^{17}$.

Neste último caso, compreender-se-ia que certa historiografia- sobretudo em épocas de maior controlo ideológico, como durante o Estado Novo (1926-1974) - tenha estudado essencialmente as épocas e os factos gloriosos, "esquecendo" aqueles em que, por vezes, se registaram determinados fracassos. Lembre-se, a propósito, o papel fulcral que as Descobertas marítimas e a Expansão têm desempenhado na História de Portugal. A propósito, notou Joaquim Barradas de Carvalho - historiador de perspectiva marxista e, por conseguinte, insuspeito - o seguinte:

«Toda a história de Portugal gira em torno dos descobrimentos marítimos e da expansão dos séculos XV e XVI. Tudo o que aconteceu antes não foi mais do que uma preparação para esses grandes empreendimentos. Tudo o que aconteceu depois foram -e são ainda (1974) — consequências desses grandes empreendimentos» ${ }^{18}$.

Provavelmente o mesmo se passará com outros povos — isto é, o procurar esquecer-se o que não agrada - , mas as derrotas mi-

${ }^{16}$ História de Portugal, dirigida por José Mattoso, 8 vols., Lisboa, eds. Círculo de Leitores e Presença, 1992-1994.

${ }^{17}$ A. José Saraiva, op. cit., p. 94.

${ }^{18}$ Joaquim Barradas de Carvalho, Rumo de Portugal. A Europa ou o Atlântico? (Uma perspectiva histórica), Lisboa, Livros Horizonte, 1974, p. 43. 
litares, sofridas por Portugal ao longo da História, raramente são recordadas pela historiografia e pela própria memória colectiva dos Portugueses ${ }^{19}$.

\subsection{Mitos e realidade}

Como é revelado pela literatura da especialidade, a mitologia tem acompanhado o Homem praticamente desde as suas origens. Independente do fundo histórico que o mito possa ter, o certo é que ele desempenha um importante papel na cultura de um povo, como já sucedia na Grécia Antiga e também noutras civilizações.

São diversos os mitos que se podem detectar na cultura e na história portuguesas. Estes vêm desde a fundação da nacionalidade (com o milagre de Ourique, em $1139^{20}$ ), ao Sebastianismo (subsequente ao desaparecimento de D. Sebastião em Alcácer Quibir, em 1578), à Maria da Fonte (1846) e ao próprio "mito imperial", ainda hoje não totalmente desvanecido.

$\mathrm{O}$ mito pode ter uma função cultural relevante, ajudando-nos a compreender e a explicar os anseios e os problemas que têm preocupado os homens. Neste sentido, o "Prometeu Agrilhoado" da mitologia grega representaria a luta titânica da Humanidade pelo progresso e desenvolvimento tecnológico-científico. Todavia, o mito pode também revelar-se contraproducente, quando é confundido com a própria realidade. Por exemplo, o mito do Sebastianismo $^{21}$ — tão presente na literatura e na história portuguesas-

${ }^{19}$ Recordem-se, apenas a título de exemplo, Alcácer Quibir (4 de Agosto de 1578) e La Lys (9 de Abril de 1918).

${ }^{20}$ Ana Isabel Carvalhão Buescu, O Milagre de Ourique e a História de Portugal de Alexandre Herculano. Uma polémica oitocentista, Lisboa, Instituto Nacional de Investigação Científica, 1987.

${ }^{21}$ João Lúcio de Azevedo, A evolução do Sebastianismo, Lisboa, Livraria Clássica 
- contribuiu para difundir a expectativa segundo a qual, em momentos de crise nacional, acabaria por vir um "D. Sebastião" qualquer, com poderes suficientes para resolver a situação de dificuldade em que o País se encontrava.

De forma análoga, também as esperanças depositadas em certas revoluções $(1820,1910,1926$ ou mesmo 1974) se transformaram, pelo menos para certas camadas da população portuguesa, em autênticos mitos, dado que as expectativas, por vezes, ultrapassaram as reais possibilidades do que os revolucionários e o próprio País podiam satisfazer. E mais recentemente (1986), com a adesão de Portugal à Comunidade Europeia/União Europeia, não se terá acreditado em um novo mito, ao esperar-se daquela a solução para muitos dos problemas que têm afectado o País?

\subsection{Razão, afectividade e imaginação}

Embora tal raramente seja reconhecido em obras sobre a história da ciência, publicadas no estrangeiro, o contributo da cultura e da prática portuguesas não deve ser esquecido, quando se estudam os alvores da ciência moderna. Com efeito, como foi evidenciado pela investigação histórica de, entre outros, os estudos de Jaime Cortesão, Joaquim Barradas de Carvalho, José Sebastião da Silva Dias e Vitorino Magalhães Godinho, o ambiente proporcionado pelos Descobrimentos portugueses foi decisivo para o arranque da cultura científica moderna. Com efeito, com experiências tão ricas e diversificadas dos nautas portugueses, da literatura de viagens e da própria cartografia, difunde-se uma mentalidade

Editora, 1918; Joel Serrão, Do Sebastianismo ao Socialismo em Portugal, Lisboa, Livros Horizonte, 1973. 
baseada no "experiencialismo" ${ }^{22}$ — ou seja, na experiência, no "know-how", na prática - , o que constitui como que um primeiro degrau para o "experimentalismo". Este, como fundamento da ciência nos últimos séculos e pedra de toque do método experimental, veio a permitir o espectacular desenvolvimento científico, como é sobejamente conhecido. Portugal contribuiu, assim, para fomentar o novo ambiente cultural então criado, o qual foi assim caracterizado por Silva Dias:

«A essência da nova óptica intelectual pode resumir-se nesta série de primazias: investigação da causalidade física em vez de investigação das causas metafísicas, observação em vez de disputa, estudo do fenómeno em vez do estudo da coisa em si, juízo de relação em vez de juízo de ser ou substância». E prossegue o autor: «Ora a energia espiritual subjacente a tais preferências parece-nos indissociável da seiva que brotava da própria acção de portugueses e espanhóis para lá da orla marítima e terrestre do "universo" tradicional. Entravam nessa seiva ingredientes fundamentais da "inteligência científica revolucionária": a descrença da ciência livresca e da epistemologia escolástica, o gosto de observar e de experimentar, a correlação da teoria e da prática, a confiança no poder da vontade humana e da razão crítica» ${ }^{23}$.

Como é sabido, Portugal, logo seguido da Espanha, não foram os únicos a exportar os novos valores culturais. Foram, contudo, os pioneiros, como é bem sabido e ainda hoje recordado. Não será necessário lembrar a chegada dos Portugueses ao Japão em meados do século XVI (1543), introduzindo naquele país a arma

J. Barradas de Carvalho, op. cit., p. 37; Maria Tereza Fraga, Humanismo e experimentalismo na cultura do século XVI, Coimbra, Livraria Almedina, 1976.

${ }^{23}$ J. S. da Silva Dias, Os Descobrimentos e a problemática cultural do século XVI, Universidade de Coimbra, 1973, p. 147. 
de fogo, inovação, na altura, muito importante e que viria a ter consequências decisivas na história e na própria cultura nipónicas.

Este contributo prestado pela Europa ao Oriente - depois seguido, até hoje, por um permanente intercâmbio entre Oriente e Ocidente - já foi assim sublinhado por um dos nossos ensaístas mais notáveis, Eduardo Lourenço, na sua obra Heterodoxia, I (Coimbra, 1949): «A inquietação universal que transformou o Japão, como está transformando a China e a índia ([estávamos em 1949], é a marca da Europa no Mundo, duma Europa onde a própria contemplação dos seus místicos se define ainda como acção» ${ }^{24}$.

Não obstante este contributo português, no século XV e inícios do XVI, a partir de então o cientismo não teve grande êxito em Portugal. Entra-se, a partir dessa altura, num período de relativa decadência, cujo estudo veio a constituir como que uma obsessão para a famosa "geração de 70" (da qual fizeram parte, entre vários outros, Antero de Quental, Ramalho Ortigão, Oliveira Martins e Alberto Sampaio) ${ }^{25}$. A propósito, notou Barradas de Carvalho:

«Julgamos ser possível surpreender por estas épocas (séculos XV-XVI) uma tradição racionalista no pensamento português, a que poderemos chamar experiencialismo do Renascimento, tradição esta que por meados do século XVI a decadência e a Inquisição haviam de fazer abortar. Portugal foi uma promessa não cumprida..., como escreveu um dia António Sérgio» ${ }^{26}$.

Eduardo Lourenço, Heterodoxia, I: Europa ou o diálogo que nos falta da permanência no mundo do espirito. O segredo de Hegel ou o equivoco da dialéctica, Coimbra, 1949, p. 31.

${ }^{25}$ A. Machado Pires, embora reconhecendo "todos os riscos de cómodas agrupações e sistematizações", elaborou um quadro da geração de 70, com quarenta e oito nomes (António Machado Pires, A ideia de decadência na geração de 70, $2^{a}$. ed., Lisboa, Vega, 1992, p. 44-45).

${ }^{26}$ J. Barradas de Carvalho, op. cit., p. 37. 
O papel negativo da Inquisição, instituída em Portugal por 1536 (reinado de D. João III), tem sido salientado por numerosos autores. Outros factores, no entanto, poderiam igualmente ser invocados. Por exemplo, terá uma certa mentalidade católica - ao invés da calvinista, em países do Norte da Europa - constituído um travão ao desenvolvimento do capitalismo em Portugal? Esta perspectiva foi intuída por Antero de Quental e Alberto Sampaio, na segunda metade do século $\mathrm{XIX}^{27}$, estando de acordo com a tese posteriormente defendida por Max Weber, na sua conhecida obra $A$ ética protestante e o espírito do capitalismo ${ }^{28}$.

Deve no entanto reconhecer-se que, mais importante do que o espírito científico e a própria racionalidade foi o papel desempenhado na cultura portuguesa pela afectividade e a imaginação. Recorro de novo à apreciação de Eduardo Lourenço — desta vez no seu notável e conhecido ensaio O labirinto da saudade-, onde se pode ler: «O verdadeiro mediador, o autêntico motor dessa metamorfose [no sentido de uma revolução cultural] é menos o intelecto, a cultura que nele ou através dele se converteu não só num obstáculo, numa forma de repetição do conformismo social, mas a imaginação» ${ }^{29}$.

Sobre a fértil imaginação, um dos elementos característicos da cultura portuguesa, podiam ainda mencionar-se diversos testemunhos, oriundos da literatura, das artes plásticas, do teatro, etc.

${ }^{27}$ Cfr. José M. Amado Mendes, Alberto Sampaio e a história económica, Guimarães, 1995, p. 373-374; Onésimo Teotónio Almeida, «Antero e Causas da Decadência dos Povos Peninsulares: entre Weber e Marx», Congresso Anteriano Internacional. Actas. 14-18. Outubro. 1991, Ponta Delgada, Universidade dos Açores, 1993, pp. 33-43.

${ }^{28}$ Max Weber, A ética protestante e o espirito do capitalismo (trad. do alemão). Lisboa, Ed. Presença, 1983.

${ }^{29}$ Eduardo Lourenço, O labirinto da saudade, $3^{\text {a }}$. ed., Lisboa, Dom Quixote, 1988, p. 52. 
Atestam-na alguns momentos altos da nossa produção literária, como sejam os do século XVI, dos anos 1830 até finais do século passado, ou mesmo nas últimas décadas do nosso século. Como sublinhou acertadamente o etnólogo Jorge Dias, «outra constante da cultura portuguesa é o profundo sentimento humano, que assenta no temperamento afectivo, amoroso e bondoso. Para o Português o coração é a medida de todas as coisas» ${ }^{30}$.

$\mathrm{O}$ que se acaba de focar, relacionado com a imaginação e a sensibilidade, é tão fundamental na cultura portuguesa que Joaquim de Carvalho o integra na caracterização do patriotismo português. Para $o$ autor, este define-se em função de três componentes fundamentais:

1) constância multissecular, que vem dos tempos pré-históricos;

2) substrato afectivo;

3) tendência saudosista ${ }^{31}$.

Este último aspecto leva-nos a considerar mais um elemento importante da cultura portuguesa, ou seja, a saudade. Acerca desta, sublinha Afonso Botelho, na obra intitulada precisamente Da Saudade ao Saudosismo (1990):

«A saudade participa da essência da história de Portugal e muitas das suas decisões capitais nela se inspiraram ou a ela se sujeitaram, pelo que não se estranha que a tendência dos que estudam a sua natureza vá no sentido de lhe reconhecer autonomia ontológica, radicada em condições étnicas peninsulares ${{ }^{32}}^{2} \mathrm{E}$

${ }^{\circledR} J o r g e \quad$ Dias, $O$ essencial sobre os elementos fundamentais da cultura portuguesa. Lisboa, Imprensa Nacional-Casa da Moeda, 1995.

"Joaquim de Carvalho, Compleição do patriotismo português. Discurso proferido no Gabinete Português de Leitura, do Rio de Janeiro, na sessão de 10 de Junho de 1953, comemorativa do Dia de Camões, Coimbra, Atlântida, 1953.

${ }^{32}$ Afonso Botelho, Da Saudade ao Saudosismo, "Biblioteca Breve", série "Pensamento e Ciência", Lisboa, Instituto de Cultura c Língua Portuguesa ( Ministério da Educação), 1990, p. 11. 
acrescenta o autor, noutro local do mesmo trabalho: «A saudade é quase um lugar comum na sensibilidade portuguesa, enquanto que a reflexão sobre ela é ainda pouco sistemática e fundamentalmente problemática» ${ }^{33}$.

Mesmo assim, dos estudos sobre o assunto, devidos, entre outros, a Carolina Michaèlis de Vasconcelos ${ }^{34}$, Joaquim de Carvalho e a Antonio José Saraiva, infere-se: a) que se trata de um sentimento, por certo não exclusivamente português, apesar de não existir vocábulo correspondente em certas línguas (como o inglês ou o francês); b) a sua origem é muito antiga, pois já aparece no cancioneiro dos séculos XIII e XV; c) surgiu no Noroeste peninsular, no território Entre Douro e Minho e na Galiza ${ }^{35}$.

Vejamos o que de essencial distingue o referido elemento da cultura portuguesa, segundo António José Saraiva:

$« \mathrm{O}$ sentimento chamado saudade caracteriza-se pela sua duplicidade contraditória: é uma dor da ausência e um comprazimento da presença, pela memória. É um estar em dois tempos e em dois sítios ao mesmo tempo, que também pode ser interpretado como uma recusa de escolher: é um não querer assumir plenamente o presente e o não querer reconhecer o passado como pretérito. Do ponto de vista da actividade, é um acelerador combinado com um travão simultâneo, se é possível usar imagens mecânicas em matéria de tanta subtileza qualitativa. De qualquer forma, é um

${ }^{33}$ A. Botelho, idem, p. 28.

${ }^{34}$ Carolina Michaèlis de Vasconcelos, A saudade portuguesa, 2*. ed., revista e aumentada, Porto. Lisboa. Rio de Janeiro, Renascença Portuguesa - Seara Nova Annuario do Brasil, 1922. Segundo a autora,«(...) já em fins do século XVI, a Saudade era considerada quasi como filosofia ou religião nacional» (op. cit., p. 36).

${ }^{35}$ Joaquim de Carvalho, Problemática da saudade, Lisboa, 1950. Sep. das Actas do XIII Congresso Luso-Espanhol para o Progresso das Ciências, 6 ${ }^{\text {a }}$. Secção (Ciências Filosóficas e Teológicas); António José Saraiva, op. cit., p. 87-88. 
sentimento complexo, mesclado, doce-amargo, pouco próprio à acção, e não deve ter contribuído pouco para que a personalidade portuguesa apareça a observadores estrangeiros como desnorteante e paradoxal» ${ }^{36}$.

Por seu turno, já D. Francisco Manuel de Melo havia salientado, na conhecida Epanaphora Amorosa III: «Florece entre os Portugueses a saudade por duas causas, mais certas em nós que em outra gente do mundo; porque de ambas essas causas tem seu princípio. Amor e ausencia são os pays da saudade; e como nosso natural he, entre as mais nações, conhecido por amoroso, e nossas dilatadas viagens ocasionão as maiores ausencias; de ahi vem, que donde se acha muito amor e ausencia larga, as saudades sejão mais certas, e esta foy sem falta a razão porque entre nós habitassem, como em seu natural centro [...]. He a saudade huma mimosa paixão da alma, e por isso tão sutil, que equivocamente se experimenta, deixando-nos indistinta a dor da satisfação. He hum mal que se esgota e hum bem que se padece» ${ }^{37}$.

Como é sabido, o próprio fado, a que alguns chamam "canção nacional", está bastante ligado à saudade e ao respectivo sentimento de saudosismo ${ }^{38}$.

${ }^{36}$ A. José Saraiva, A cultura em Portugal, I, p. 88.

${ }^{37}$ D. Francisco Manuel de Melo, «Descobrimento da Ilha da Madeira. Anno 1420. Epanaphora amorosa terceira», Epanáforas de vária história portuguesa, $3^{\mathrm{a}}$. ed., revista e anotada por Edgar Prestage, Coimbra, Imprensa da Universidade, 1931, p. 224.

${ }^{38}$ Como é do conhecimento geral, a saudade constitui também tema recorrente na poesia lírica portuguesa. Recordo apenas alguns exemplos: António Sardinha, Na Côrte da Saudade. Sonetos de Toledo, Coimbra, "LUMEN"-Empresa Internacional Editora, 1922; Guilherme de Faria, Saudade minha (poesias escolhidas), Lisboa, 1929; António Corrêa d'Oliveira, Saudade nossa, Lisboa, ed. fora do mercado, 1944. 


\subsection{Défice de espírito capitalista?}

Reflectir-se-ão os aspectos focados também no comportamento da sociedade portuguesa, no que concerne à dinâmica económica? Ter-lhe-ão escasseado racionalidade, ambição, espírito de lucro e de iniciativa, para iniciativas arrojadas e rentáveis, isto é, espirito capitalista, tal como este foi caracterizado por Werner Sombart? ${ }^{39}$

Independentemente das respostas a dar à questão formulada, o certo é que os Portugueses não beneficiaram substancialmente do grande império que possuíram, parte dele até recentemente (1975). Terá havido um certo bloqueio por parte de «fidalgos e clérigos parasitários», como sugere António José Saraiva? $?^{40}$. Pelo menos houve uma nítida preferência pela distribuição, pelo comércio - a que António Sérgio chamou "política do transporte" ${ }^{\text {—41 }}$, relativamente à produção ou à fixação. Mesmo assim, com que resultados? Já foi salientado, acerca deste aspecto:

«Os Portugueses são os iniciadores do mercado mundial em grande escala e nele participaram sucessivamente com as especiarias do Oriente, o açúcar do Brasil, os escravos, o ouro de Minas, o café do Brasil e de Angola, etc. Lisboa foi um dos centros comerciais do comércio intercontinental. Todavia nunca aqui se formou um pólo capitalista». E acrescenta o mesmo autor: «O trabalho dos nossos camponeses produziu uma mercadoria de alta qualidade, que é o vinho do Porto. Mas os nossos homens do

39 Werner Sombart, Le bourgeois. Contribution à l'histoire morale et iittelectuelle de l'homme économique moderne. Paris, Payot, 1926.

40 A. José Saraiva, idem, p. 100.

"António Sérgio, «As duas principais actividades económicas. A política da fixação e a politica do transporte», Breve interpretação da História de Portugal. Obras completas, 12. ed., Lisboa, Livraria Sá da Costa Editora, 1985, pp. 27-30. 
negócio não souberam comercializá-lo, e as marcas comerciais são inglesas ${ }^{42}$.

Por último, vejamos a articulação da cultura portuguesa com outras culturas.

\section{Uma Cultura com Vocação Universalista}

Jaime Cortesão, a propósito das consequências da expansão ultramarina, salientou o papel dos Portugueses na construção do "humanismo universalista"43. Este pode ser perspectivado como tendo sido um primeiro passo para a formação da macrocultura da "aldeia global", em que o Mundo se transformou, neste final do século XX.

Numa breve síntese pode dizer-se que, desde o período pré-nacional, os contactos culturais com outros povos foram uma constante na História de Portugal. Assim, uma primeira fase desde a Pré-História até ao século VIII -, a Península Ibérica recebeu a influência de vários povos, que nela se fixaram. O povo português herdou, daqueles, um significativo legado pré-nacional, como bem notou Orlando Ribeiro ${ }^{44}$. Durante os primeiros séculos da nacionalidade (séculos XII-XIV), além das relações, por vezes conflituosas, com os reinos vizinhos peninsulares, estabeleceram-se contactos comerciais com países do Norte da Europa. Por exemplo, o início das relações políticas e diplomáticas, de Portugal com a Inglaterra, remontam a 17 de Fevereiro de 1294, reinado

${ }^{42}$ A. José Saraiva, idem. p. 99-100.

${ }^{43}$ Jaime Cortesão, História dos Descobrimentos Portugueses, vol. III, Lisboa, Circulo de Leitores, 1979, p. 205-219.

${ }^{44}$ O. Ribeiro, op.cit., p. 25-42. 
de D. Dinis ${ }^{45}$. Para o efeito, a localização do País, à beira do mar, foi um factor extraordinariamente positivo. Aliás, na opinião de José Mattoso, o próprio carácter expansivo da cultura portuguesa deve-se também à localização do País, junto ao $\operatorname{mar}^{46}$.

Resolvida a crise de 1383-85 e estabelecidas relações de boa vizinhança com Castela (1411), Portugal inicia a sua expansão, com a tomada de Ceuta (1415). Os Portugueses começam a espalhar-se pelos quatro continentes. Inicia-se então o período áureo da História de Portugal, o qual, em termos de memória histórica, passou a ocupar um lugar privilegiado. Durante 500 anos, como notou Eduardo Lourenço, a lembrança da acção expansionista e imperial passou a constituir «o núcleo da imagem de Portugal» ${ }^{47}$.

Com a queda do império, iniciada no século XVII (no Oriente) e continuada com a independência do Brasil (1822), nova expansão de Portugueses e da cultura portuguesa se verifica, agora já não através de marinheiros mas de emigrantes. Saíram de Portugal entre três e quatro milhões - um terço da população actual -, dos anos 60 do século passado até à década de 70 do nosso século. Por sua vez, só numa década (1964-1974), «Portugal "exportou" para a Europa mais de 1,5 milhão de portugueses (...), ou seja, o equivalente a metade da população activa em 1970» ${ }^{48}$. Após o ciclo da emigração para o Brasil (até cerca de 1930), aquela descobriu um novo destino: a Europa do Mercado Comum, hoje União

${ }^{45}$ António Álvaro Dória, «Inglaterra. Relações de Portugal com a...», Joel Serrão (dir.), Dicionário de História de Portugal, vol. II, Lisboa, Iniciativas Editoriais, 1965, p. 544.

${ }^{46}$ José Mattoso, $O$ essencial..., p. 15-16.

"7 Eduardo Lourenço, O labirinto da saudade, p. 17.

${ }^{48}$ Graça Franco, «Dez anos. Metade da população activa deixou o pais. O sobressalto modernizador», Público, de 21.08.1996, p. 3; António Barreto (org.), A situação social em Portugal, 1960-1995. Lisboa, Instituto de Ciências Sociais, 1996. p. 41 e 72. 
Europeia. Aqui trabalham e estudam, hoje, milhões de Portugueses, muitos já da segunda geração e que, provavelmente, não mais regressarão ao País, a título definitivo.

Actualmente, a cultura portuguesa continua a "misturar-se" e a cooperar com outras culturas, não só através dos emigrantes tradicionais - frequentemente de parcos recursos, económicos e culturais -, mas também de cientistas, professores, estudantes, intelectuais, técnicos e empresários, comerciantes e industriais. Todos os anos Portugal recebe milhões de estrangeiros - entre os quais se contam centenas de estudantes -, ao mesmo tempo que muitos Portugueses também viajam. Podemos dizer que, não obstante as condições terem mudado radicalmente, o "humanismo universalista", criado a partir do Renascimento e com o contributo decisivo dos Portugueses e de outros povos europeus, continua a dar os seus frutos. Recordem-se, inclusive, os permanentes contactos com países que, outrora, foram colónias portuguesas: o Brasil (país independente desde 1822 e os Países Africanos de expressão portuguesa, independentes desde 1975, na sequência da Revolução do 25 de Abril de 1974, em Portugal).

Um dos exemplos desses contactos encontra-se precisamente no intercâmbio que temos vindo a efectuar com Universidades Japonesas, nomeadamente de Kyoto (Kyoto University e Kyoto University of Foreign Studies), que gostaríamos de ver reforçado e continuado. Além do mais, ao intensificarmos contactos culturais, estamos simultaneamente a trabalhar para a manutenção da paz e do entendimento entre os povos, o que deve constituir um dos objectivos prioritários de todas as nações. 